surfaces of the globe from the time of the morning maximum to the afternoon minimum.

The following are the four phases of the diurnal variation of the pressure in summer at a few of the more strictly insular stations :-

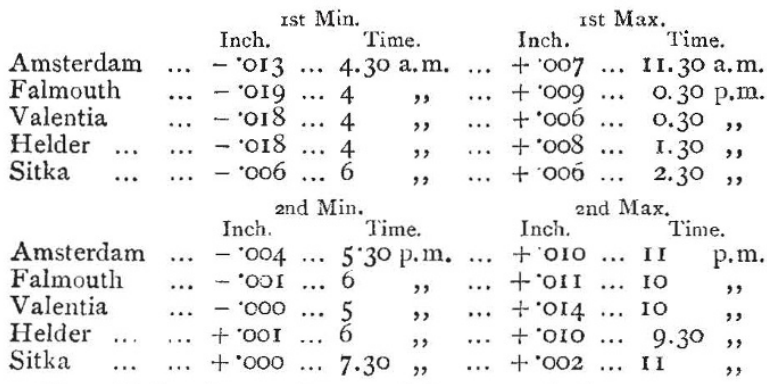

The chief points to be noted here are the large amounts of the Ist min, and the small amounts and retardation in the times of occurrence of the Ist max. and 2 nd min. All these peculiarities are presented in a still stronger form by the results of June taken by itself. Thus at Sitka the times of the four phases are 7 a.m., 3 p.m., 7.30 p.m., and I I p.m., and the and min. and and max. become very small. It is only, however, over the open sea in the higher latitudes where the 2 nd $\mathrm{min}$. and 2 nd max. disappear, resulting in one minimum in the early morning and one maximum in the early afternoon. This afternoon maximum therefore really represents the a.m. max. of the lower latitudes of the ocean and of land surfaces-which phase of the pressure occurs at different hours from 7 a.m. to 3 p.m. according to latitude and geographical position-and hence subsequent to the a.m. or Ist max. the lines representing the diurnal barometric variation are everywhere to be represented by minus signs.

The highly important result remains that over the open sea in the higher latitudes of the Atlantic and the Southern Ocean the diurnal curve of pressure, as shown by the observations of the Norwegian and Challenger Expeditions, exhibit only one minimum and one maximum and that the curve generally resembles the curve of temperature. Hann's remark that "in the daytime the air in the upper strata above the land flows towards the sea, occasioning an increase of pressure, which even on the coast asserts itself by retarding the morning maximum and the afternoon minimum; in the evening and at night this process is reversed, a current of air in the higher strata flows from the sea to the land; hence the pressure increases, diminishing on the coast, and the evening maximum becomes inconsiderable," simply accounts for part of the phenomena as observed near the coast and at no great distance out a: sea. It leaves, however, the outstanding feature of the diurnal atmospheric pressure over the open seas of high latitudes untouched and unexplained. To this point we shall return on an early occasion.

The curves of the diurnal distribution of the pressure of the aqueous vapour of the air are very interesting. Grouping the three series together and bloxaming the results, we obtain a curve of great simplicity, showing one maximum and one minimum, the maximum rising $0.1 \mathrm{~mm}$. above the daily mean from II a.m. to $3 \mathrm{p.m}$., and the minimum falling $0^{\circ} \mathrm{rmm}$. below it from $10 \mathrm{p.m}$. to $4 \mathrm{a} . \mathrm{m}$. In other words, the curve of the force of vapour substantially agrees with the curve of temperature, and it agrees with the same curve obtained from the open sea observations of the Challenger. The curve for the Challenger observations taken near land shows a dip from about I I a.m. to 3 p.m. which is quite decided, though not of so pronounced a cbaracter as is seen over land during the summer months. A slight dip occurs in the sefarate curves of the Norwegian Expeditions for I 876 and I 877 , which doubtless is due to the comparative proximity to land where several of the observations were made. This reduction in the amount of the aqueous vapour which is observed to occur during the hottest hours of the day is due to the descent of the drier air of the upper regions to take the place of the air which ascends from the heated surfaces of the earth. This diminution of the aqueous vapour of the air is not restricted to the air over the heated surfaces, but, as shown by the Challenger and Norwegian observations, it extends for some distance out at sea, probably as far as the indraught of air from the sea towards the land heated by the noonday sun is felt.

The curve of the diurnal velocity of the wind deduced from the whole of the observations and bloxamed reveals the fact that the influence of the lower pressure which obtains over the interior of Scandinavia, as compared with that round its coasts during the hottest months of the year and the hottest hours of the day, extends much further out at sea than might have been supposed, and the curve of the force of the aqueous vapour just referred to corroborates this view. The curve of the diurnal velocity of the wind substantially agrees with that of the temperature.

The same overpowering influence of the sun is equally seen in the diurnal distribution of the temperature of the surface of the sea, the curve for which agrees with that for the temperature of the air. The curves for the separate years show, however, such striking differences in the mean amounts of the diurnal variation, and particularly in the hours of occurrence of the maximum excesses above the day means, as to show that a less close approximation to the true diurnal curve has been arrived at for the temperature of the sea than for any of the other meteorological elements. In carrying out this work and discussing the results, Prof. Mobn has clearly made a contribution of the greatest importance to the physical geography of the sea.

ALEXANDER BUCHAN

\section{VIENNA INTERNATIONAL ELECTRICAL EXHIBITION}

THE Vienna Electrical Exhibition was opened to-day to the public. The patron of the Exhibition, the Crown Prince Rudolph, the Portuguese Crown Prince, the Princes of the Imperial family, the higher functionaries of the State, and the Foreign Commissioners were present at the opening ceremony. The attendance of the public was small; only 4000 persons have visited the Exhibition to-day, the weather being rainy. The Crown Prince, in replying to the address delivered by Baron Erlanger, the president of the Exhibition Commission, said that it did not seem to be only by chance that the third and greatest Electrical Exhibition is held in Vienna-in the town in which, in I833, lucifer matches were invented by Preschel, from which, in 1837 , the stearine candle found its way through the whole world, and where the lighting of streets by gas had been suggested by the Moravian, Zinser, before it was carried out in England.

The Exhibition, though still incomplete, promises a good display illustrative of the great progress made in practical electricity during recent years, and showing how the application of electricity for the various purposes of industry and of daily life is becoming more and more common. So far as we can see now, although the work of installation of the machinery and apparatus is not yet completed, the Exhibition will stand comparison with previous exhibitions as to the number and variety of exhibits and the arrangement of the whole. From the official catalogue published to-day we learn that there are 579 exhibitors, 223 of whom are from Austria, I33 from France, 68 from Germany, 27 from Russia, I6 from Italy, Io from Denmark, 13 from America, and 27 from England. Thus the Exhibition is rather a Continental one, 
and it is generally much regretted that so few exhibits have been sent from England, which has played a leading part in the development of applied electricity.

A special feature of the Vienna Exhibition is the building itself - the Rotunda, built by Scott Russell, the eminent engineer, in 1873 , covering with its annexes and courts a space of 33,000 square metres. The vast dome is $79 \mathrm{~m}$. in height, and three galleries, the highest-the lantern gallery-being $66 \mathrm{~m}$. above the ground, make it well adapted for illumination by electric lamps. Everything has been done to make the Exhibition as interesting and attractive as possible. Between the Rotunda and the Praterstern an electric tramway will run. The Rotunda is brought into telephonic connection with the Opera. A gallery of the Exhibition building contains a model theatre lighted by incandescent lamps, where ballets will be performed and scientific lectures given by eminent specialists, while another gallery contains beautifully arranged and furnished interiors and the picture gallery. In the machine rooms the great boilers make a gigantic impression; they will supply the various motors with 1400 horse-power to drive the electric machinery for lighting and transmission of motive power. In the nave are arranged the exhibits of different railway companies and also various scientific apparatus, of which further details will be given in subsequent communications.

Vienna, August I6

\section{NOTES}

WE understand that Her Majesty's Government having through the Foreign Office been invited to appoint delegates to the International Geodetic Congress to be held at Rome in October next, at which the adoption of an international common meridian and common time for railway and telegraph purposes is to be discussed, the Lords of the Committee of Council on Education appointed a Committee to report on the subject. The Committee consisted of the Astronomer-Royal, General Cooke, C.B., R.E. (Iate Director-General of the Ordnance Survey), General Strachey, C.S.I., R.E. (Member of the India Council), and Col. Donnelly, R.E. (Secretary of the Science and Art Department). In consequence of their Report, the Treasury have consented to provide the travelling and personal expenses of two delegates. We are glad to say that the Science and Art Department, in concert with the Foreign Office, have appointed the Astronomer-Royal and Col. A. R. Clarke, C.B., R.E., F.R.S., to represent this country, and that they have consented to act.

THE local secretaries at Southport have been exerting themselves to make the visit of the British Association a success. Excursions are arranged for Saturday the 22nd and Thursday the 27th of September. The Association has not met in Lancashire since the meeting at Liverpool in 1870 under the presidency of Prof. Huxley, and it is believed that the industries of the county have since then so developed and expanded as to open up fresh sources of interest to the chemist, the engineer, and the economist. It is believed that ample and convenient accommodation for a full meeting of the Association has been secured. The Winter Gardens have been engaged for the exclusive use of the Associatio:, and in them will be given the Presidential Address and evening lec ures, and in them will also be held the conversazioni. The spacious assembly room in the Cambridge Hall will be devoted to the purposes of a reception room, and suitable halls have been acquired for the use of the various sections. Numerous excursions are in process of arrangement. Among these is a visit to Stonyhurst College, the observatory, museum, library, collection of ecclesiastical vestments, and grounds, which are extremely interesting. The Abram Colliery, near Wigan, will be open to inspection, as will also the Wigan Coal and Iron
Company's pits and ironworks. Messrs. Platt Brothers and Co. have offered to show a party of members of the Association over their extensive machine works at Oldham, and certain large cotton mills in the same town will be open to visitors on the same day. A geological excursion will be made to the neighbourhood of Clitheroe and the Victoria Caves, which it is hoped will be personally conducted by Mr. R. H. Tiddeman, M. A., F.G.S., who made the geological survey of the district. Another party will visit Furness Abbey and the Lake District. The Earls of Derby, Crawford and Balcarres, and Lathom, and Mr. Weld-Blundell of Ince Blundell, will throw open their grounds to members of the Association, and at some of these places garden parties $\mathrm{w}$ ill be given. There is abundant hotel accom. modation of the best kind, as well as good hydropathic establishments and numerous excellent lodging.houses. A list of all these has been prepared and published in pamphlet form.

THE French Association began its meetings at Rouen on Thursday last, when the president, M. Frédéric Passy, gave an address on the history of political economy. The revenue of the Association during the past year amounted to 85,677 francs, of which 13,900 francs were devoted to purposes of research. The capital of the Association reaches the large sum of 454,526 francs. On Friday evening M. Hatt, hydrographer to the French navy, lectured on the transit of Venus in December, 1882, while another lecture on the transmission of force was given by Prof. Comberousse. Considerable time was devoted on Saturday in the Engineering Section to proposals for improving the navigation of the Seine. Various excursions have been made during the week, and will be continued to morrow and following days.

Mr. BELT has been commissioned by the employés of the late Mr. William Spottiswoode, President of the Royal Society, to execute a monument to his memory, and the site for its erection will be in front of Her Majesty's Printing Office.

VIENNA papers announce the death at Botzen, in the Tyrol, on August 10, of the Austrian Vice-Admiral, Baron von Wiillerstorf-Urbair, one of the most learned and scientific officers that the Austrian navy has ever possessed, and who has con. tributed greatly to its professional improvement. He was not originally intended for a naval life, and was educated in the engineering officers' school at Tulla, where he acquired a great reputation, especially on account of his mathematical talents and proficiency. But a combination of circumstances led to his being transferred to the navy at the age of eighteen. $\mathrm{He}$ was almost at once allowed leave of absence to continue his scientific studies at Vienna, where he pursued astronomy and meteorology under Littrow, at that time director of the Vienna Observatory. In 1839, when only twenty-four years of age, Willerstorf was appointed to organise the marine observatory, and from that time till $\mathrm{i} 848$ he acted as director of that institu. tion, and as professor of astronomy and navigation at the Naval Academy in Venice. In 1848 he returned to active service, becoming commodore in 1857 , when he took command of the Novara on the celebrated expedition around the world, the first of the kind undertaken by the Austrian Government. In I $86 \mathrm{r}$, being then rear-admiral, he became commander at the Venice station, and in 1864, during the Danish war, he was appointed to the command of the combined Austrian and Prussian squadron in the North Sea. In 1865 he became Minister of Commerce, a position which he held till 1867 , when failure of health compelled him to retire from active life at the early age of fifty-two. $\mathrm{He}$ was a member of the Austrian Academy of Sciences, and of many other scientific bodies. He was sixty-eight years of age when he died.

THE liberality of Finland to science is exemplary. The Senate has voted a sum of about 8000 . for hydrographical 